SISTEMA
ELETRONIICO
DE REVISTAS
SER I UfPR

\title{
Percepção ambiental e mineração de agregados: o olhar da população urbano-rural de Ourém, Pará, Brasil
}

\section{Environmental perception and mining of aggregates: the view of the urban-rural population of Ourém, Pará, Brazil}

\author{
Yuri Cavaleiro de Macêdo COELHO ${ }^{1 *}$, Flávia Cristina Araújo LUCAS ${ }^{1}$, Priscila Sanjuan de Medeiros \\ SARMENTO $^{1}$ \\ ${ }^{1}$ Programa de Pós-Graduação em Ciências Ambientais (PPGCA), Universidade do Estado do Pará (UEPA), Belém, PA, Brasil. \\ *E-mail de contato: yuricoelhos15@hotmail.com
}

Artigo recebido em 31 de julho de 2018, versão final aceita em 9 de janeiro de 2020, publicado em 3 de abril de 2020.

RESUMO: A mineração tem se destacado em razão da diversidade e abundância de produtos que podem ser explorados dos ambientes naturais. Entretanto, esta atividade está fortemente associada a cenários de degradação ambiental e conflitos sociais. Em Ourém, município do nordeste paraense, a lavra de agregados para construção civil (areia, argila e seixo) é uma prática que já vem acontecendo há alguns anos. Diante disto, a presente pesquisa analisa a percepção ambiental de moradores atingidos direta ou indiretamente por atividade mineradora do referido município. A coleta de dados ocorreu com 154 residentes, utilizando: formulários estruturados; observação participante; conversas informais; entrevistas semiestruturadas e registros fotográficos. Os resultados mostram que os indivíduos estão mais preocupados com os problemas relacionados à segurança e ao emprego, em detrimento dos danos causados ao meio ambiente, inclusive com a mineração. Estatisticamente, as pessoas mais preocupadas com os agravos ambientais são os moradores com idade mais avançada, que residem há mais de 31 anos no município e possuem ocupação fixa. Sobre o trabalho das mineradoras, a população evidencia em proporção bem maior os impactos socioambientais negativos do que os positivos. Todavia, as pessoas demonstraram estar habituadas com os efeitos prejudicais da mineração e pouco se mobilizam para solicitar reparação de danos e contrapartidas sociais. As informações obtidas a partir dessas investigações são de suma importância como um registro de evidência científica disponível para a população e suas lideranças, tendo potencial de contribuir na articulação entre poder público e sociedade civil, bem como na elaboração de políticas públicas com base em projetos de diagnóstico ambiental que reflitam a visão dos diferentes atores envolvidos.

Palavras-chave: impactos da mineração; conflitos socioambientais; desenvolvimento econômico; Amazônia.

Desenvolv. e Meio Ambiente usa uma Licença Creative Commons - Atribuição-NãoComercial-SemDerivações 4.0 Internacional 
ABSTRACT: Mining has stood out because of the diversity and abundance of products that can be exploited from natural environments. However, this activity is strongly associated with scenarios of environmental degradation and social conflicts. In Ourém, northeastern Pará, the exploitation of aggregates for civil construction (sand, clay and pebble) is a practice that has been happening for some years. In view of this, the present research aimed to analyze the environmental perception of residents directly or indirectly affected by the mining activity of said municipality. Data collection occurred with 154 residents, using: structured forms; participant observation; informal conversations; semi-structured interviews and photographic records. The results showed that individuals are more concerned with safety and employment issues, to the detriment of damage to the environment, including mining. Statistically, the people who are most concerned about environmental damage are older residents, who have lived in the municipality for more than 31 years and have a fixed occupation. Regarding the work of the mining companies, the population considers that there is a much higher proportion of negative socio-environmental impacts than the positive ones. However, people demonstrate have shown that they are accustomed to the harmful effects of mining and are not very active in requesting compensation for damages or any social compensation. The information obtained from these investigations is of paramount importance as a record of scientific evidence available to the population and its leaders, having the potential to contribute in the articulation between public power and civil society and in the elaboration of public policies based on environmental diagnosis projects that reflect the vision of the different actors involved.

Keywords: mining impacts; socio-environmental conflicts; economic development; Amazon.

\section{Introdução}

O desenvolvimento econômico mundial exerce ação marcante no aumento da exploração de recursos naturais não-renováveis, especialmente combustíveis fósseis e minérios usados na elaboração e/ou manutenção de bens de consumo. À vista disso, de forma oposta ao funcionamento do expansionismo capitalista, o meio ambiente está sendo dilapidado em sua finitude, o que traz sérias implicações para a sociedade e para o equilíbrio dos ecossistemas (Rampazzo, 1996).

A instalação de grandes projetos, como hidrelétricas, a expansão da fronteira agrícola e a extração mineral degradam fortemente o bioma da Amazônia, aumentando, sobretudo, os índices de desflorestamento (Fearnside, 2015). Sobre a mineração, Palheta da Silva \& da Silva (2016) afirmaram que, independentemente do material extraído e a escala de produção das mineradoras amazônicas, essa prática é considerada fortemente erosiva e predatória da natureza e do ser humano. Em torno dessa problemática, verifica-se uma rede complexa de partes interessadas, com vieses político, cultural, econômico, ambiental e social, abrangendo empresas de mineração, órgãos legisladores e reguladores, a população local, mineiros ilegais e um mercado global (Arango et al., 2017).

Os agregados para construção civil (areia, seixo e brita) são recursos que contribuem para o desenvolvimento das sociedades humanas (Blengini et al., 2012) e encontram-se, mercadologicamente, com demanda crescente de produção (Aguirre \& Hennies, 2010). A extração desses minérios é de suma importância no setor mineral brasileiro (CETEM, 2009), gerando rendimento médio de 623 milhões de toneladas/ano (Mancin, 2012). Embora esses valores sejam expressivos para a economia 
nacional, estas matérias-primas são obtidas, geralmente, em minas informais, por vezes clandestinas, de pequeno porte e distribuídas a micromercados regionalizados (La Serna \& Rezende, 2013).

A exploração de agregados impacta negativamente o meio ambiente em diferentes proporções e períodos de duração, sendo os prejuízos identificados desde os procedimentos para abertura das cavas, como decapeamento e desmonte, até o fechamento delas (Faleiro \& Lopes, 2010). Os danos observados nas fases de lavra e transporte englobam, sobretudo: alteração do lençol freático; poluição sonora, visual, da água, ar e solo; impactos sobre a fauna e flora; assoreamento e erosão; mobilização da terra; instabilidade de taludes, encostas e terrenos em geral; lançamentos de fragmentos dos materiais e vibrações resultantes da britagem; entre outros, que afetam os meios físico, biótico e antrópico (Bacci et al., 2006; Vieira \& Viana, 2016; Amorim et al., 2016).

O estado do Pará, localizado na Amazônia Oriental, é o maior produtor de agregados da região Norte (IBRAM, 2012). O município de Ourém (PA), locus deste estudo, é um dos grandes fornecedores de seixo, brita e areia, alcançando no ano de 2006 uma produção média de 700 m³/dia, a maior do estado (FANEP, 2006). Como não foram encontrados dados oficiais recentes a esse respeito, estima-se que, atualmente, a produção seja muito maior, visto que Pires (2014), ao estudar apenas duas empresas no município (dentre as outras várias legais e clandestinas por lá implantadas), descreveu uma produção de mais de $350 \mathrm{~m}^{3} /$ dia.

Ao ser extraído do leito do principal rio do município, o rio Guamá, ou da terra firme, o minério é processado, por vezes beneficiado, e, em seguida, é destinado, na maior parte, ao abastecimento (1) da construção civil de grandes centros urbanos, como Belém, capital do Estado do Pará, e Castanhal (Matos, 2007, Pires, 2014), e (2) da indústria de pavimentação asfáltica, localizada em municípios limítrofes.

Pesquisas realizadas por Carvalho et al. (2013) e Souza et al. (2016), em Ourém, apontaram graves consequências ambientais provenientes da extração de agregados: as "montanhas" de resíduos estéreis, provenientes da lavagem do seixo, sofrem ações dos ventos e das chuvas, tais como: o assoreamento dos corpos hídricos; os despejos aleatórios dos resíduos da lavagem do seixo; o esgotamento da fertilidade do solo, decorrente da movimentação dos horizontes; os prejuízos ao processo de restauração florestal; a suspensão de poeira nas cavas e nas estradas, dentre outros.

A implantação de áreas de mineração, na maioria das vezes, acontece sem que ocorra um diálogo participativo que atenda às expectativas, anseios e preocupações das comunidades que serão atingidas direta ou indiretamente, o que resulta em relações de conflito entre o minerador e a população (Farias, 2002). A respeito disso, Whyte (1977) explicou que as vivências, os sentimentos e os significados que os indivíduos têm dos ambientes devem ser reconhecidos, pois manifestam, através da percepção ambiental, algo além da experiência sensorial direta. Ferreira \& Coutinho (2000) frisaram que estas percepções estão condicionadas a fatores (1) imprimidos pela sociedade (educacionais e culturais) e (2) derivados das relações do ser com o ambiente (afetivos e sensitivos). Portanto, evidenciar a percepção e os comportamentos ambientais de moradores residentes em zonas de conflito pode nortear a capacidade de responder a múltiplas preocupações, atuais e/ou futuras (White \& Hunter, 2009). 
Na Amazônia, são raras as pesquisas de percepção sobre os contextos mineradores. Matlaba et al. (2017) foram pioneiros em examinar percepções sobre a mineração industrial, tendo como estudo de caso a empresa multinacional Vale S.A., instalada no município de Canaã dos Carajás (PA). No referido artigo, discutiram-se as realidades e conflitos socioeconômicos e culturais advindos desse empreendimento, localizado numa das áreas mais biodiversas do planeta.

Frente ao exposto, objetivou-se, com o presente estudo, analisar a percepção ambiental de moradores do município de Ourém, Pará, atingidos por atividade mineradora. Para alcançar o objetivo, traçaram-se as seguintes questões norteadoras: (i) Como a população de Ourém observa os problemas do município em aspectos gerais e ambientais? (ii) Os residentes observam os impactos positivos e negativos advindos da mineração de agregados? (iii) Como as percepções declaradas se associam umas às outras e aos traços sociodemográficos da amostra? (iv) A população se organiza para questionar os impactos negativos da mineração?

\section{Procedimentos metodológicos}

\section{1. Área de estudo}

A cidade de Ourém situa-se na Mesorregião Nordeste Paraense, Microrregião do Guamá (S 01 ${ }^{\circ}$ 33' 07'; W 47 06' 52") (Figura 1), e limita-se com os municípios de Capitão Poço, Bonito, Capanema, São Miguel do Guamá e Santa Luzia do Pará. A sede municipal está distante $182 \mathrm{~km}$ de Belém, capital do estado do Pará. Segundo o último Censo Demográfico (IBGE, 2010), ocupa uma área de

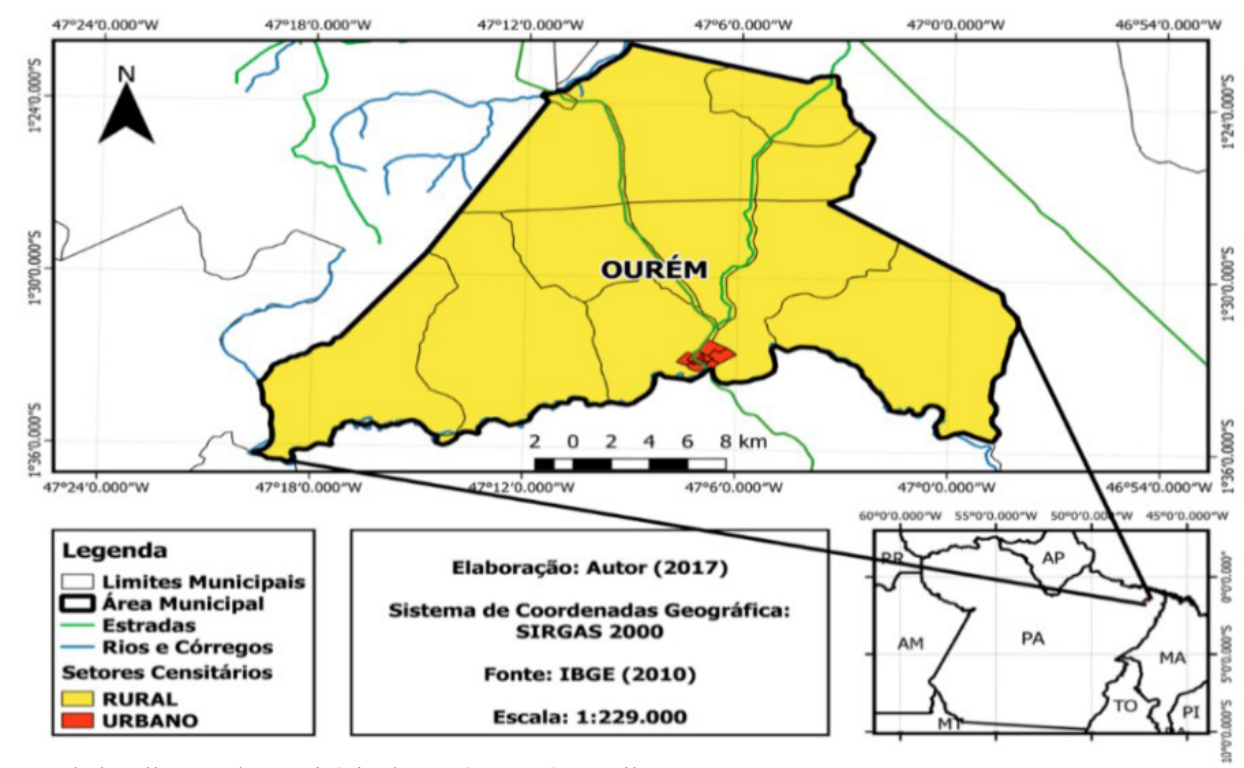

FIGURA 1 - Mapa de localização do município de Ourém, Pará, Brasil.

FONTE: elaboração dos autores com base nos dados do IBGE (2010). 
$562,388 \mathrm{~km}^{2}$, com população estimada em 16.311 habitantes, e densidade demográfica de $29 \mathrm{hab} . \mathrm{km}^{2}$.

O município é rico em paisagens naturais, sendo privilegiado pela beleza cênica das matas ciliares, com a ocorrência de espécies de grande destaque madeireiro (Matos, 2007). Ademais, destaca-se pelo potencial hídrico, constituído pelos rios Guamá, que banha a orla da sede municipal, Carité e Caeté, bem como pequenos olhos e cursos d'água (igarapés), sendo uma forte atração turística nos períodos de veraneio (Matos, 2007).

Morfoestruturalmente, o município integra a região do Planalto Rebaixado da Amazônia, que possui altimetrias entre 50-200m (Furtado \& Ponte, 2013). Apresenta predominância de solos distróficos, de textura média e argilosa, com propriedades que possibilitam a exploração extrativista de materiais, como: areia, seixo, cascalho, brita, piçarra e argila (FANEP, 2006; FAPESPA, 2012).

Quanto à cobertura vegetal original, Ourém preserva apenas $9,2 \%$ ou $46 \mathrm{~km}^{2}$ (Anuário do Pará, 2017), restando pequenos estoques de floresta original, os quais estão situados principalmente próximos ao limítrofe sul, com o município de Capitão Poço (Souza et al., 2016). Nessas áreas alteradas predominam as florestas sucessionais e as de várzea banhadas pelo rio Guamá (Anuário do Pará, 2017). O desmatamento é bastante visível tanto nas proximidades do centro urbano, quanto nas estradas de acesso à sede municipal (Geovane et al., 2012). Um dos fatores que contribuem para esta problemática é a mineração de agregados para a construção civil, que, há décadas, consolida-se na base econômica do município (Matos, 2007; Ourém, 2015).

\subsection{Coleta de dados}

A pesquisa ocorreu entre os meses de setembro e novembro de 2017. Pessoas de 19 comunidades rurais ${ }^{1}$ e 11 bairros da região urbana foram consultadas. $\mathrm{O}$ universo amostral foi constituído por 154 interlocutores ${ }^{2}$, admitindo-se coeficiente de segurança de $90 \%$ e margem de erro de $8 \%$, calculado com base no número total de habitantes do município conferido pelo Censo Demográfico de 2010. A amostragem foi probabilística do tipo estratificada (Albuquerque et al., 2010), selecionando-se os seguintes critérios: local de residência (urbano e rural) e sexo, conforme os dados do Censo Demográfico de 2010 para o município.

Escolheu-se a pesquisa domiciliar para abordagem dos participantes, por promover aproximação com os sujeitos e as realidades investigadas e, por conseguinte, melhor detalhamento dos assuntos estudados (UN, 2008). O respondente era o membro designado pela família para representar a Unidade Familiar, sendo todos escutados individualmente. Durante o diálogo, caso julgassem necessário, seus parentes poderiam manifestar opiniões, percepções e/ou acrescentar informações (Lobato et al., 2017), as quais foram descritas no caderno de campo.

\footnotetext{
${ }^{1}$ As comunidades Sítio Nazaré e Igarapé-Grande, apesar de se localizarem geograficamente no município de Capitão Poço, margem sul do Rio Guamá, foram incluídas na pesquisa devido à proximidade e ao fato de grande parte dos moradores utilizarem rotineiramente os serviços públicos de Ourém e/ou são eleitores do município locus deste estudo.

${ }^{2}$ Todos os interlocutores assinaram o Termo de Consentimento Livre e Esclarecido, elaborado de acordo com a Resolução 466/2012, concordando em participar da pesquisa de forma voluntária e anônima. Este estudo é parte integrante do projeto intitulado: "Mineração, Ambiente e Sociedade: a percepção de moradores de Ourém, Pará, Brasil”, aprovado pelo Comitê de Ética em Pesquisa (CEP), sob o número de registro 2.993.460.
} 
Utilizou-se uma abordagem de métodos mistos (Plank et al., 2016), que consiste em integrar dados qualitativos e quantitativos. Para tanto, foram aproveitadas as informações contidas nos formulários padronizados com 23 questões abertas e fechadas, assim como nas conversas informais; entrevistas semiestruturadas, na observação não participante e registros fotográficos (Gil, 2008; Albuquerque et al., 2010; Marconi \& Lakatos, 2010). Desta forma, foi possível confirmar e/ou complementar os esclarecimentos fornecidos pelos sujeitos, o que favorece as possibilidades analíticas (Johnson \& Onwuebuzie, 2004; Creswell, 2009; Small, 2011).

O formulário foi construído a partir de buscas por documentos e pesquisas especializadas em caracterização ambiental por percepção pública (Rodrigues et al., 2012; SOS Mata Atlântica, 2015). As perguntas do formulário abordavam, além da sociodemografia (idade, tempo e local de moradia, sexo, escolaridade, renda, ocupação e proximidade com a mina), aspectos relacionados ao conhecimento e percepção de impactos ambientais e de saúde decorrente da mineração de agregados, bem como o envolvimento e a mobilização da comunidade em relação aos efeitos da atividade. As perguntas fechadas foram elaboradas tendo em vista respostas dicotômicas ou de escolha múltipla, em que os interrogados, ao analisar as questões, escolhiam uma ou mais opções conforme suas percepções. As abertas solicitavam explicações das fechadas. Os percentuais apresentados nas duas primeiras análises do subitem 3.2. somam mais de $100 \%$, pois, exclusivamente para estas perguntas, solicitaram-se três diferentes respostas de cada interlocutor.

Para avaliar o tempo de aplicação e possíveis erros de interpretação ou equívocos nos itens, realizou-se, antes do início da investigação, uma testagem preliminar do formulário com 60 estudantes da rede pública de Ourém, maiores de 18 anos.

As entrevistas e conversas foram registradas em áudio e em notas de respostas tomadas em cadernos de campo. As gravações foram transcritas e, posteriormente, junto às anotações de campo, sintetizadas para o procedimento de análise.

\subsection{Tratamento dos dados}

Os dados das perguntas fechadas foram sistematizados em planilha do software Microsoft Office Excel

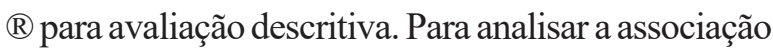
de perguntas com respostas dicotômicas ou de escolha múltipla, entre elas e/ou com as orientações socioeconômicas e demográficas, foram feitas tabelas de contingência, em que a independência entre suas células foi verificada pelo teste Qui-quadrado, com correção de Yates, se necessário. Quando os resultados se mostraram significativos $(p<0,05)$, tabelas de contingência foram desmembradas e suas células analisadas duas a duas. No teste de independência, a hipótese nula previa independência entre as variáveis. Sendo assim, quando $\mathrm{p}<0,05$, rejeita-se a hipótese nula, admitindo que as variáveis (respostas) são dependentes. O perfil da amostra incluído nas análises estatísticas está listado na Tabela 1 , obedecendo às categorizações expostas nesta. As interpretações propostas estão embasadas em Gotelli \& Ellison (2010) e foram executadas no software estatístico R (R Development Core Team 2011).

Já os dados de perguntas abertas, falas de entrevistas e notas de campo, foram analisados pela técnica de análise de conteúdo, obedecendo-se às etapas definidas por Bardin: "a pré-análise, a exploração do material; e o tratamento dos resultados, a inferência e a interpretação" (Bardin, 2010). 
Os dados coletados são apresentados sobrepostos, conforme proposto por Plank et al. (2016) para o método de pesquisa misto. Assim, frequências, porcentagens e falas são usadas na discussão.

\section{Resultados e discussão}

\subsection{Perfil dos respondentes}

Os interlocutores encontravam-se na faixa etária de 18 a 81 anos, em média 33,4 anos, com escolaridade predominante para o ensino médio (52,6\%). As ocupações profissionais foram variadas: funcionários formais e informais de organizações públicas e privadas $(28,6 \%)$; estudantes de qualquer nível e modalidade educacional (27,3\%); desempregados, autônomos, domésticas e aposentados $(23,4 \%)$; agricultores e lavradores (20,7\%). Grande parte dos entrevistados reside a cerca de dois quilômetros $(\mathrm{km})$ da seixeira mais próxima. O tempo de moradia variou de 6 meses a 81 anos (27,3 anos em média), o que para Sousa et al. (2016) caracteriza uma amostra com grau de conhecimento satisfatório da área de estudo. A renda salarial média foi igual ou menor a um salário mínimo, R\$937,00. Este perfil corresponde em muitos aspectos aos encontrados em outros estudos com municípios e comunidades paraenses (Brito et al., 2015; Lobato et al., 2017). A seguir, apresenta-se o perfil sociodemográfico e econômico dos respondentes (Tabela 1).

\subsection{Percepção socioambiental geral do município de Ourém}

Os três principais problemas do município de Ourém destacados pelos sujeitos estão relacionados à segurança $(83,1 \%)$, ao trabalho/emprego $(82,5 \%)$ e às questões ambientais $(56,5 \%)$. Aspectos relativos à saúde, educação, infraestrutura, esporte, cultura e lazer foram citados secundariamente. Tais preocupações, ressaltadas mais no âmbito social do que ambiental, foram também evidenciadas no município de Luís Eduardo Magalhães (BA) (Santos \& Souza, 2015) e em Carmo da Mata (MG) (Rabelo, 2017), que apontaram os sérios impactos ao meio advindos do agronegócio e da mineração de grafite, respectivamente.

$\mathrm{O}$ foco atribuído à segurança pode ser reflexo do expressivo aumento na taxa de homicídios de Ourém. Em uma década, o município, que até os anos 2000 não apresentava casos de assassinatos, passou a ter uma taxa de homicídios acima do nível epidêmico, mas abaixo da média nacional (10 a 26 mortes por 100 mil habitantes) (Waiselfisz, 2011). Segundo Waiselfisz (2015), isto pode ser consequência dos processos de interiorização e disseminação da criminalidade, que, geralmente, ocorrem em estados tradicionalmente violentos, como o Pará, deslocando os polos dinâmicos de crimes dos municípios de grande porte para os de pequeno e médio. Para Andrade \& Braga-Filho (2016), o aumento da violência nos interiores decorre da desconcentração do crescimento e da difusão do desenvolvimento econômico em direção a estes locais.

O número de pessoas que observaram os problemas ambientais como preocupantes em Ourém $(n=87)$ foi maior entre os interlocutores mais velhos, com tempo de moradia no município superior a 31 anos, que trabalham em empresas privadas ou são servidores públicos (funcionários) (Tabela 2) e independe da escolaridade, renda, proximidade da mina, sexo e zona de moradia (Tabela 2).

Pesquisas que analisaram a percepção sobre poluição ambiental e sua relação com fatores so- 
TABELA 1 - Perfil demográfico e socioeconômico do universo amostral.

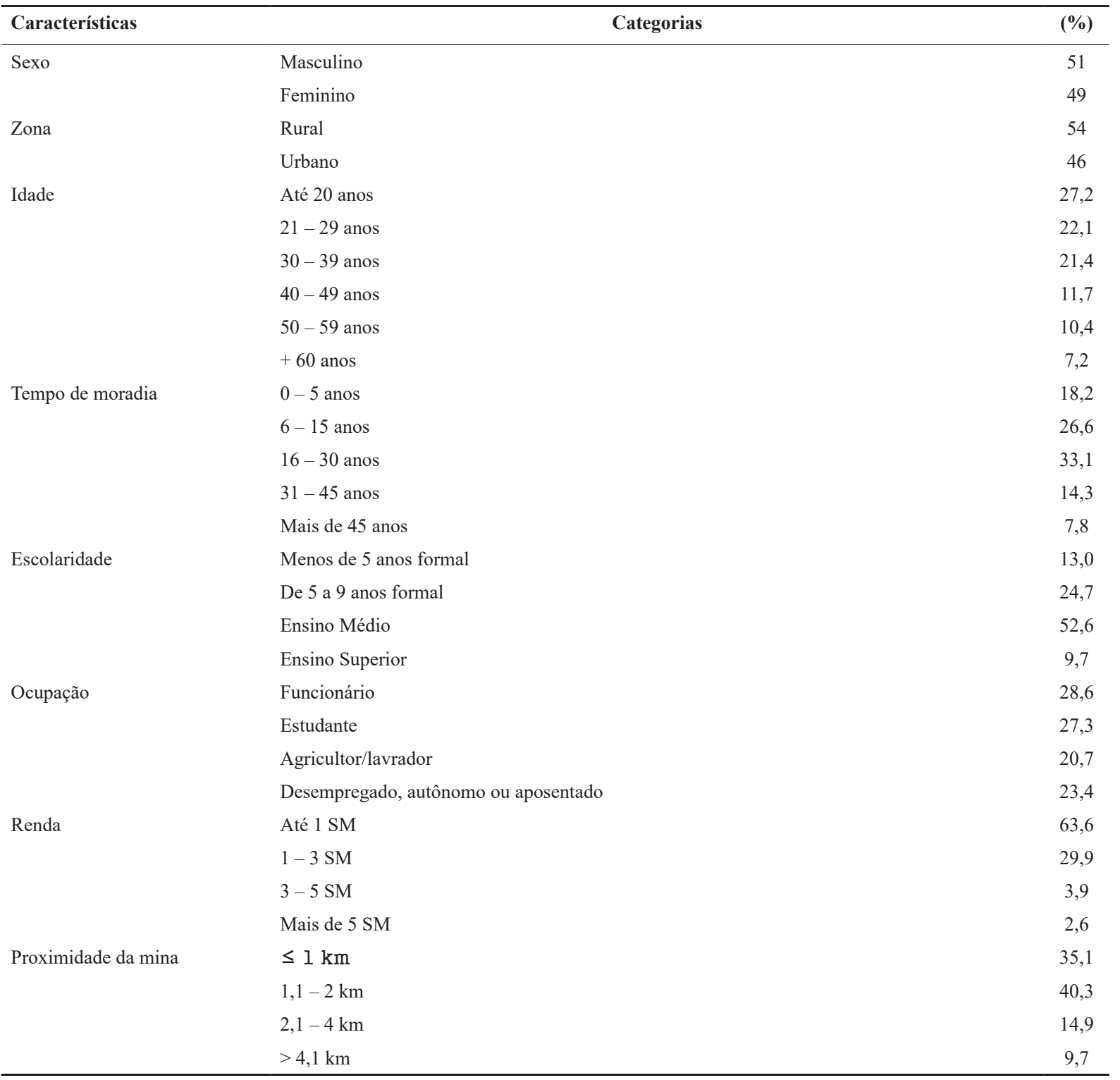

Legenda: (SM) Salário Mínimo. 
ciodemográficos constataram que a idade (Shen \& Saijo, 2008; Shi \& He, 2012) e o tempo de residência (Shi \& He, 2012) são variáveis que contribuem para uma maior preocupação com o ambiente e observação de danos. Shi \& He (2012) discutem que moradores antigos e mais velhos são mais sensíveis aos danos da poluição e os que mais exigem melhores condições ambientais. No município aqui estudado, presumiu-se que os resultados encontrados estejam relacionados ao fato de que reclamações sobre problemas de saúde, como insônia/distúrbios do sono, tosses e alergias, bem como a verificação de mudanças na estética da paisagem serem mais comuns em pessoas mais velhas e que moram há mais tempo no município, justamente por conviver e sofrer com os efeitos da atividade por um período mais longo, além de acompanhar as pressões e transformações nos meios físico, biológico e antrópico.

Alguns estudos indicaram que a ocupação profissional pode ou não influenciar a preocupação ambiental das pessoas (Van Liere \& Dunlap; 1980; Jones \& Dunlap, 1992; Shi \& He, 2012). Em Ourém, cogitou-se que a associação detectada estatisticamente com esta variável ocorra devido às rotinas e práticas de trabalho que fazem com que as pessoas visualizem mais os impactos ao meio, tais como: o deslocamento diário pelo centro e zonas mais afastadas da cidade; as nítidas mudanças na paisagem e no uso da terra; o acesso a informações que chegam por acesso virtual. Entretanto, não é possível realizar generalizações com esses dados, haja vista que aspectos ambientais, culturais, históricos, políticos e econômicos específicos de cada realidade e/ou grupo podem afetar o entendimento, comportamento e gerenciamento de recursos (Hamilton et al., 2014).

Dos três principais problemas ambientais identificados, 92,9\% dos participantes citaram a poluição e o assoreamento dos corpos hídricos da região como algo que mais perturba o meio ambiente: "Eu me lembro a fundura que era esse igarapé que passa aqui no fundo do terreno, a água cobria a gente. A gente se divertia muito lá. Agora, mal serve pra lavar roupa de tão seco que tá!" (Moradora da Comunidade do Rio Vermelho, 59 anos).

O desmatamento e as queimadas foram também considerados graves, totalizando $71,4 \%$ e $43,5 \%$, respectivamente; já o lixo e a poluição do ar foram citados com menor relevância. Esses distúrbios mostraram-se nos estudos de Sousa et al. (2016) - que foi feito no município de Bacabeira (MA), localizado na rota de escoamento da produção minerária do Pará - e Carvalho \& Domingues (2016), que sinalizaram o avanço da exploração madeireira e, consequentemente, o desflorestamen-

TABELA 2 - Associação de dados sociodemográficos entre os que percebem o meio ambiente como um problema grave em Ourém, Pará.

\begin{tabular}{ccccccccc}
\hline & $\mathbf{S}$ & $\mathbf{Z}$ & $\mathbf{I}$ & T. M. & E. & O. & R & P. M. \\
\cline { 2 - 7 } & & & & Teste Qui-quadrado - Valor $\mathbf{p}$ & \\
\hline $\begin{array}{c}\text { Meio Ambiente como principal problema } \\
(\mathrm{n}=87)\end{array}$ & 0,629 & 0,59 & $0,005^{*}$ & $0,04^{*}$ & 0,43 & $0,01^{*}$ & 0,49 & 0,29 \\
\hline
\end{tabular}

Legenda: $\mathrm{S}=$ Sexo; $\mathrm{Z}=$ Zona; $\mathrm{I}=$ Idade; T.M. = Tempo de Moradia; $\mathrm{E}=$ Escolaridade; $\mathrm{O}=$ Ocupação; $\mathrm{R}=$ Renda; P.M. = Proximidade da Mina $* \mathrm{p}<0,05$ : estatisticamente significativo.

FONTE: dados da pesquisa. 
to no Nordeste Paraense, mesorregião em que se localiza Ourém.

A precariedade dos serviços de saneamento (apenas 12,7\% de domicílios possui esgotamento sanitário adequado) (IBGE, 2010), as formas inadequadas de captação da água e descarte de resíduos nos rios por atividades de agricultura, pecuária e mineração, e a memória afetiva de pessoas afetadas em seus modos de vida pelas mudanças no meio ambiente local são fatores vinculados à alta percepção de perturbações aos corpos hídricos de Ourém. Constatou-se que, conforme os pressupostos de Tuan (1980), os respondentes manifestaram um sentimento topofílico baseado em vivências e vínculos afetivos com o local. No município de Skjåk, na Noruega, afetado por usina hidrelétrica, Vorkinn \& Riese (2001) verificaram o apego das pessoas por lugares específicos, alegando que isto se desenvolve através das experiências individuais com o ambiente físico.

Diegues (2000), ao abordar o papel das comunidades na conservação de ambientes e paisagens, incluindo suas práticas e saberes, também reflete que impactos de diferentes naturezas são causados em função da implantação de projetos, sem que se leve em conta as necessidades dos grupos sociais envolvidos e a inter-relação que desenvolvem com o ecossistema que os cercam. Para o autor, há fortes vínculos entre a identidade cultural e o local em que se vive, o que denota a dependência dos recursos existentes no ambiente para a reprodução social.

Os próprios entrevistados se responsabilizam/ culpam pelos transtornos ambientais de Ourém, pois, dominantemente, manifestam que a população é a principal responsável por eles (35,7\%). As razões para isto estão concentradas nos agravos ocasionados: pelas construções irregulares de balneários particulares; pela queima de lixo; pelas ligações clandestinas para escoamento de esgoto domiciliar; e pelo manejo da terra de forma intensiva com o cultivo de feijão, mandioca, milho, pimenta-do-reino e laranja. A seguinte fala ratifica o que foi exposto: "O vizinho aqui do lado, pra construir uma área de lazer pra família perto do igarapé, saiu derrubando tudo quando foi árvore, colocando saco de cimento pra represa a água e o igarapé ficar mais fundo na parte dele [...]" (Morador da Comunidade do Rio Vermelho, 81 anos). Igualmente, em Ferreira et al. (2018), os interlocutores assumiram suas responsabilidades pelos problemas ambientais do município minerador São Gonçalo do Rio Abaixo (MG).

Com responsabilidade secundária aparecem os donos de seixeiras (26\%), conhecidos como "seixeiros", vistos como pessoas que exploram, degradam e modificam paisagens: "Esse povo [seixeiros] vem praqui, compram a terra da gente, mexem nelas, tiram a nossa riqueza e levam tudo embora. Só o que resta pra gente são essas montanhas de areia [montes de estéreis] e os buracos em todo canto por onde se anda na cidade" (Morador da comunidade do Rio Vermelho, 60 anos).

A Prefeitura Municipal (17,5\%), os órgãos de fiscalização ambiental em geral (13\%) - como: IBAMA (Instituto Brasileiro do Meio Ambiente e dos Recursos Naturais Renováveis), EMATER (Empresa de Assistência Técnica e Extensão Rural do Estado do Pará), SEMMA (Secretaria Municipal de Meio Ambiente) etc. -, os agricultores e os latifundiários (7,8\%) foram os menos citados. Em consonância com os resultados desta pesquisa, o público pesquisado por Rodrigues et al. (2017), no distrito de Antônio Pereira, Ouro Preto (MG), afirmou que os moradores locais são os principais 
responsáveis pela deterioração ambiental, seguido das grandes mineradoras e da Prefeitura Municipal.

Metade dos entrevistados declarou que, se pudessem escolher, privilegiariam políticas públicas de estímulo ao desenvolvimento econômico (geração de emprego e renda) do município de Ourém, enquanto um percentual também expressivo optaria por políticas de proteção ambiental $(44,1 \%)$. Os demais $(5,9 \%)$ atentaram para a possibilidade de articular estratégias que buscassem conciliar, a longo prazo, os dois cenários políticos destacados. Estes dados ressaltam as perturbações ambientais e o respectivo incômodo dos interlocutores com elas, bem como o desejo em conservar e restaurar o meio local, mas, ao mesmo tempo, querem ver a região como um "progresso". White \& Hunter (2009) constataram uma percepção similar a esta entre o público consultado na zona costeira de Gana, África Ocidental, que aponta intenso impacto antrópico ao meio por conta do aumento da atividade econômica.

\subsection{Percepção de danos socioambientais causados pela mineração de agregados}

A maior parcela dos indivíduos consultados $(90,9 \%)$ reconheceu/visualizou algum tipo de impacto negativo das seixeiras ao meio ambiente. Desses efeitos negativos, $90,9 \%$ dos interlocutores, a grande maioria se referiu à degradação do solo e da vegetação e à poluição da água como impactos da mineração: "[...] onde a gente via mato, agora tá tudo esburacado e cheio de montanha de areia que não presta pra nada. Isso vai ficar assim pra sempre, por que depois que o seixo para de dar, o lugar não presta pra plantar nada depois" (Morador da Comunidade do Cearazinho, 62 anos); “[...] essa seixeira aqui de perto secou o igarapé do Cafeteua" (Moradora do Bairro do Porão, 43 anos).

Em menor frequência, foram indicados a poluição sonora, a poluição do ar, as alterações climáticas (aumento da temperatura, mudança no período e tempo de duração da cheia do Rio Guamá) e os desequilíbrios na biodiversidade (desaparecimento da fauna nativa, diminuição na quantidade de peixes). Segundo Mechi \& Sanches (2010) e Ibrahim et al. (2018), as perturbações ocasionadas por estes empreendimentos afetam o meio físico, biótico e antrópico, em diferentes intensidades nas diversas etapas.

A degradação do solo e da vegetação chama bastante atenção dada as alterações na paisagem causadas pela mineração, observadas em áreas próximas ao centro urbano e nas zonas mais afastadas, como: (1) numerosos e volumosos montes de estéreis, inclusive próximo às atuais ou antigas áreas de mata; (2) reservatórios de rejeitos; e (3) imensas crateras, inundadas ou não, deixadas nos terrenos após a extração.

A percepção dos transtornos aos recursos hídricos ocorre devido (1) aos transbordos ou rompimentos das barragens de rejeitos, (2) as manchas de óleos e graxas no curso de rios, presumivelmente despejados pelas mineradoras em limites superiores ao máximo (20 mg/L) estabelecido na NBR 14063 (ABNT, 1998), (3) ao aumento da área e do volume de material sedimentado no rio Guamá, localizados próximos à orla da cidade e (4) a intensificação das secas dos igarapés. Segundo Bossi et al. (2010), o pensamento comum sobre impactos socioambientais da mineração está ligado à formação de buracos, disputa pela terra e contaminação das águas.

Alguns moradores destacaram que a mineração diminuiu a quantidade de peixes nos rios do 
município, inviabilizando a pesca e afugentando animais terrestres, o que leva ao desaparecimento da fauna cinegética (tatu, porco-do-mato e algumas espécies de aves) e afeta tanto as formas de obtenção de renda, quanto as práticas culturais de alimentação e lazer das comunidades. No município de Porto Grande (AP), Pinheiro (2016) constatou que todas as fases do processo de mineração de seixo e areia impactam negativamente a fauna, afetando os moradores, sobretudo pela falta de peixes. Em trabalhos de percepção, cujo tema é a mineração, dos mais variados tipos de minério, são comuns as queixas com a segurança da água e qualidade do ar (Adeola \& Olushola, 2016; Li et al., 2017).

Em Ourém, a poluição do ar é sentida mais fortemente por moradores que estão muito próximos às cavas, aos locais de beneficiamento, como as olarias, ou às estradas de escoamento da produção. O tráfego intenso de veículos, que transportam o minério pelas estradas do município, representa um risco à segurança da população, pois, causam acidentes e levantam partículas de poeira, devido à falta de pavimentação nas estradas e ao não enlonamento da carga, conforme o regulamentado pelo Código de Trânsito Brasileiro (Brasil, 1997), o que danifica outros veículos e habitações à beira das estradas, bem como pode vir a afetar a saúde da população. Logo, a logística de escoamento dos minerais gera comprometimentos tão fortes quanto outras etapas do processo (lavra e beneficiamento) (Bossi et al., 2010).

As consequências da mineração de agregados na saúde são percebidas por 20,1\% dos interlocutores, percentual relativamente baixo, quando se considera a intensidade e o tempo de exploração mineral no município. Os moradores que mais manifestam essa percepção estão situados próximos aos empreendimentos ou às estradas. Foram descritas mais frequentemente sintomatologias para doenças respiratórias, como: asma, bronquite, rinite e sinusite, sendo estas relacionadas à poeira em suspensão, com maior recorrência no período de poucas chuvas (de julho a dezembro).

A percepção do risco da mineração à saúde, principalmente como fonte de problemas respiratórios, foi mais intensa entre moradores de Petrolina (PE) (Silva et al., 2018) que moram mais próximo das minas. Adeola \& Olushola (2016) declararam que, embora as preocupações com o pó sejam maiores a 100 metros da fonte, a poeira pode afetar comunidades que distam até $1 \mathrm{~km}$. As doenças citadas pelos residentes de Ourém foram as mesmas relatadas pelos comunitários de Abeokuta Ogun, na Nigéria, afetados por uma pedreira (Olusegun et al., 2009).

Originados de cavas abandonadas ou sobre-exploradas, os lagos de mineração em Ourém também são fontes de preocupações dos moradores devido (1) às incipientes políticas de recuperação e manutenção, (2) às formas de aproveitamento destas áreas e (3) aos riscos à saúde. Atualmente, alguns destes espaços estão a céu aberto junto aos montes de estéreis e reservatórios de rejeitos. No entendimento dos entrevistados, estes espaços constituem perigo à saúde e à segurança da população pelo aumento da população de insetos, sapos e cobras nas comunidades próximas, além de riscos de afogamento e transmissão de doenças como micoses, em razão da alta profundidade e da balneabilidade.

A maioria das cavas para extração de agregados resulta em lagoas que acabam esquecidas e em processo de eutrofização ou são destinadas à piscicultura (Mechi \& Sanches, 2010). O abandono e a influência antrópica nestes lagos, de acordo com 
Hinwood et al. (2009), podem torná-los pontos potenciais de proliferação de patógenos e transmissão de doenças. No distrito de Geita, na Tanzânia, os poços desprotegidos da mineração de ouro formam campos propícios de veiculação de doenças, tanto pela água, quanto por vetores, como mosquitos (Kitula, 2006). Com efeito, ao analisar as cavas abandonadas e alagadas da mineração de argila em Marabá, no Pará, Mello et al. (2017) reconheceram os riscos eminentes à saúde das comunidades locais ligadas a estas zonas, pelos mesmos motivos evidenciados em Ourém.

\subsection{Percepção sobre os benefícios $d a$ mineração de agregados}

Dos entrevistados, $32,6 \%$ enxergaram vantagens com a presença das mineradoras em Ourém. A maior parte $(40,7 \%)$ sinalizou como benefícios mais importantes a geração de empregos e/ou o baixo custo dos produtos das seixeiras. Segundo o Departamento Nacional de Produção Mineral - DNPM (DNPM, 2017), o setor vem gerando saldo positivo de mão de obra para Ourém e o salário médio do trabalhador formal desse ramo está em torno de $\mathrm{R} \$ 1.752,88$.

Melhorias na cidade adquiridas com a exploração do seixo foram mencionadas por alguns dos participantes desse estudo, Pode-se interpretar este fato como uma troca de favores entre determinados setores da sociedade, conforme relato da proprietária de uma seixeira ativa há mais de 40 anos no município: "[...] o prefeito manda tirar muita areia daqui para as obras deles ou doar pro povo [...] a gente sempre procura ajudar como pode, já fizemos três escolinhas para as crianças daqui, dando de um tudo. Só faço entregar pro prefeito pagar as profes- soras" (Dona de Seixeira, 73 anos). De acordo com Lopes-Passos et al. (2017), o discurso de "progresso" local, normalmente propagado por mineradoras e forças políticas, é empregado para encobrir injustiças ambientais e desigualdades sociais.

Ademais, a presença da seixeira é vista também, por uma minoria, como algo que desperta atenção dos órgãos de fiscalização ambiental para o município, como SEMMA, DNPM, IBAMA etc., por estes possuírem jurisdição para monitorar e controlar a exploração ambiental: "Se não existisse esse povo aqui [seixeiros], isso tudo ia ficar a Deus dará e pior do que tá... Aí que ninguém grande ia vim aqui ver. Pelo menos, até tem uma pressãozinha pra eles cuidarem das matas e dos igarapés" (Moradora da Comunidade do Rio Grande, 53 anos).

Os relatos de moradores confirmaram que as mineradoras - ao serem supervisionadas, principalmente a maioria não legalizada - utilizam estratégias para burlar autos de infração e Relatórios de Controle Ambiental, através do suborno de fiscais, funcionamento noturno (quando as fiscalizações são menos frequentes), escoamento da produção por vias clandestinas, diversificação dos locais de extração e lavagem etc. Assim, reitera-se a incapacidade e idoneidade fiscal dos órgãos de controle em punir as infrações ambientais na Amazônia, expressas similarmente no estudo de Brito \& Barreto (2006).

\subsection{Fatores que dificultam a percepção de beneficios da mineração de agregados}

De acordo com o exposto, as pessoas enxergam mais danos do que vantagens na mineração de agregados em Ourém. Todavia, estas percepções não estão estatisticamente associadas $\left(\chi^{2}=1,37\right.$; 
correção de Yates $=0,77 ; p=0,24)$, ou seja, o reconhecimento de danos independe de as pessoas identificarem ou não os benefícios. Da mesma maneira, os residentes consultados por Plank et al. (2016), em Western Victoria, na Austrália, reconheceram que os impactos negativos do setor excediam os benefícios.

Os respondentes que não observam vantagens nas seixeiras do município $(67,4 \%)$, em geral, destacam que o setor produz poucos efeitos positivos sobre a taxa de desemprego do município. Os benefícios incipientes com ofertas de emprego e geração de renda para trabalhadores de mineração foram identificados nas regiões de Gana, investigadas por Ayelazuno (2014), e previsto por Gunzburger et al. (2017) para futuros sítios de extração de carvão em Lorraine, na França.

O processo de mecanização foi indicado como uma das causas da redução do número de postos de trabalhos na atividade. A seguir, encontram-se as afirmações para estes fatos: "[...] essas seixeiras só são boas pros donos. O povo não vê um tostão. Nas máquinas é que eles colocam um ou outro peão daqui pra pegar no pesado." (Moradora da Comunidade do Furo Novo, 45 anos); "[...] uns vinte ou trinta anos atrás, eram mais de 60 homens para tirar pedra daqui. Hoje, com as máquinas todas, se tiver 15 é muito" (Morador da comunidade do Rio Vermelho, 81 anos).

No Peru, uma grande empresa na comunidade Hualgayoc, ao implantar um modelo moderno de exploração mineral, restringiu as possibilidades laborais dos mineradores nativos, transformando-os apenas em indivíduos da Área de Influência Direta (AID) (Penafiel, 2017). Concorda-se, assim, com Santos (2002), que caracterizou a mineração empresarial pela reduzida quantidade de trabalhadores e uso intensivo de capital e tecnologia.
A recente instabilidade financeira do Brasil foi um outro fator percebido como um problema, o qual vem afetando o acesso e a permanência dos funcionários nas mineradoras de Ourém. Muitos interlocutores declararam terem sido demitidos em decorrência deste fato, pelo menos nos últimos três anos. Esta realidade foi confirmada pela dona de uma das maiores seixeiras do município: “[...] $o$ nosso quadro [de funcionários] era de 33 pessoas, ai veio a crise e a gente teve que baixar pra uns 18 " (Dona de Seixeira, 73 anos).

Estas observações convergem com o evidenciado por Matos \& Ferreira (2017), quando afirmaram que, em meados de 2014, os níveis de emprego no Brasil começaram a cair por conta de forte recessão econômica no país, iniciada em 2013. No Pará, conforme o DNPM (2017), verificou-se decrescimento na geração de empregos no setor mineral a partir do segundo semestre de 2016, com queda de $0,9 \%$ no estoque de trabalhadores na atividade até junho de 2017. Entretanto, ao afirmar que a mineração está gerando saldo positivo de mão de obra para o município, o referido documento fala de uma realidade contrária à observada em campo.

Além do exposto, os moradores percebem que a baixa oferta de trabalhos formais, registrados em carteira no processo de produção de agregados em Ourém, é também reflexo da clandestinidade dos empreendimentos. Os respondentes descreveram a maioria dos seixeiros como não nativos, exploradores por essência, "blindados" pela expressividade política, força econômica e uso da violência, conforme os seguintes relatos: "De dia, se você for lá, parece que tá abandonado, mas não tá não. Eles tão trabalhando tudo de madrugada com medo das fiscalizações." (Moradora da Comunidade do Furo 
Novo, 46 anos); " $O$ dono de muitas dessas seixeiras é o prefeito de $X X X^{3}$. Quem é que vai mexer com o homem sabendo do dinheiro que ele tem? É capaz dele mandar matar nós." (Morador do Bairro do Porão, 36 anos).

A ilegalidade é mais um dos agravantes da mineração no Brasil, pois os empreendimentos operam sem pesquisas prévias de impactos socioambientais e planejamento de recuperação de áreas degradadas (Correia \& Pereira, 2016), fomentando a exploração desmedida e o trabalho informal.

Outro motivo que não gera a percepção de benefícios diz respeito às ações mitigadoras por parte das seixeiras para contornar as perturbações geradas, que, segundo os moradores, são raras e se concretizam, basicamente, em pequenas ações para reduzir a poeira, como a umidificação das vias de escoamento dos minerais localizadas próximas a comunidades e o enlonamento da carga nos caminhões que transportam os produtos: "De tanto o povo falar que ia fechar a via, eles [seixeiros] começaram a jogar água pra poeira sentar." (Morador da Comunidade do Mocambo, 42 anos); "Na estrada era um inferno! Era muito vidro de carro trincado, quebrado, por causa de pedrinha que caía das carretas. Agora, até que alguns caçambeiros têm colocado um encerado em cima da carga pra não acontecer mais isso" (Morador da Comunidade do Curuçá, 63 anos).

Estes "reparos" executados normalmente pelas empresas mineradoras (Santos et al., 2015) estão muito aquém do recomendado. Desde os procedimentos de lavra até o fechamento, devem ser incluídos condicionantes nos projetos de mine- ração, para que os impactos de diversas naturezas sejam amenizados, abrangendo controle das águas, restauração das áreas degradadas, redução de ruídos e emissão de partículas, dentre outros (Bacci et al., 2006).

Ao analisarem estes múltiplos cenários que envolvem a mineração de agregados em Ourém, numa escala de cinco pontos (em que a pontuação máxima 10 representava o "ótimo", e a mínima 2, o "péssimo"), em média, os entrevistados consideraram a atividade como razoável $(6,41)$ para a população como um todo. Entretanto, as pessoas que visualizaram os danos da mineração perceberam-na como ruim/péssima para a sociedade $\left(\chi^{2}=11,33\right.$, $\mathrm{p}=0,003)$. Já quem a vê como benéfica afirmou ser ótima/boa $\left(\chi^{2}=41,54, p<0,001\right)$. Desta forma, verificou-se coerência na percepção dos interlocutores sobre a lavra de agregados no município.

\subsection{Comportamento da população frente aos} cenários da mineração de agregados

Grande parte dos entrevistados (88,9\%) nunca denunciou a poluição das mineradoras e justificou tal fato com a desesperança com os resultados da denúncia ( $43,1 \%)$, não querer envolvimento com o assunto $(28,5 \%)$, esperar a mobilização de outras pessoas $(11,7 \%)$, desconhecer a quem/onde denunciar $(6,5 \%)$, falta de apoio $(1,4 \%)$ ou desconhecer o que denunciar $(0,7 \%)$; contudo $8 \%$ não justificaram.

Os meios utilizados por aqueles que já realizaram algum tipo de queixa ambiental no município $(11,1 \%)$ foram diversos, como: abaixo-assinados, entregues à Secretaria de Meio Ambiente e Agri-

${ }^{3} \mathrm{O}$ nome do município foi ocultado da fala do interlocutor com o objetivo de preservar a identidade do sujeito a quem este se referiu. 
cultura (41,2\%); denúncias verbais $(23,8 \%)$, feitas diretamente no Fórum Municipal, na Prefeitura e à presidência da associação de moradores; manifestações com bloqueio de vias (17,5\%); e postagens em mídias sociais $(17,5 \%)$, como blogs.

Em Itabira (MG), Guimarães \& Milanez (2017) verificaram que, da mesma forma que em Ourém, a população apresentou baixo grau de mobilização social para contestar a presença de uma mineradora e suas consequências. No mesmo município, Silva \& Souza (2012) apontaram que a mineradora também exercia forte poder imobilizador na sociedade. Na contramão disso, Araújo et al. (2014) e Jerônimo \& Souza (2015) destacaram casos de comunidades que, ao se organizarem, impediram a instalação ou modificaram substancialmente os projetos mineradores que as afetariam.

Em Ourém, não foi observada a existência de movimentos e/ou grupos organizados atentos aos danos causados por esse setor, para representar e articular a população em prol da implementação de medidas mitigadoras e melhora de suas condições de vida. Segundo relatos, líderes comunitários exercem este papel quando os impactos são fontes de muitas reclamações: "[...] de tanto o pessoal falar, o presidente daqui da comunidade juntou umas pessoas, inclusive eu, e a gente fechou a pista. Só assim que a gente conseguiu que eles [seixeiros] molhassem a pista pelo menos uma vez no dia pra diminuir a poeira" (Moradora da Comunidade do Mocambo, 44 anos).

Em Marabá e Canaã dos Carajás, Congilio \& Moreira (2016) relataram que movimentos de resistência e mobilização social contra os impactos das mineradoras estão cada vez mais intensos e articulados com organizações que os empoderam e os divulgam, o que vêm possibilitando amplia- ção de contrapartidas sociais. A participação na renda da extração do minério e a construção de um hospital, salas de aula e sistema de tratamento de água são alguns dos retornos ofertados à população pela empresa que extrai bauxita em Juruti, no Pará, conquistas resultantes de ampla mobilização social (Araújo et al., 2014).

Os entrevistados argumentam que uma eventual desativação compulsória das minas de Ourém seria uma medida positiva $(58,4 \%)$, pois promoveria bem-estar social $(82,2 \%)$ ou proteção do patrimônio natural $(17,8 \%)$. Em termos estatísticos, a percepção destas pessoas, independentemente do motivo, não está associada à observação de transtornos que a atividade causa no município $\left(\chi^{2}=4,13\right.$ correção de Yates $=2,97 ; \mathrm{p}=0,08)$. Contudo, para Silva $\&$ Ramos (2015), o fechamento das minas, muitas vezes, apresenta repercussões indesejadas, vinculadas a questões ambientais, econômicas e sociais.

$37,7 \%$ consideraram que o fechamento das minas poderia ser uma medida negativa ( $3,9 \%$ não souberam opinar), afirmando que o desemprego aumentaria e os produtos para construção civil ficariam mais caros $(86,2 \%)$ ou que o desenvolvimento do município seria afetado (13,8\%). Essas pessoas conseguem identificar benefícios com a instalação das seixeiras $\left(\chi^{2}=8,66\right.$, correção de Yates $=7,66$, $\mathrm{p}=0,005)$ e têm ou tiveram algum tipo de vínculo com os empreendimentos $\left(\chi^{2}=5,42\right.$; correção de Yates $=0,01 ; \mathrm{p}=0,03)$. Diante disso, para que o encerramento da atividade mineira ocorra com segurança, recomenda-se a execução de um Plano de Fechamento de Mina, avaliado pela ANM e órgão ambiental competente, que, dentre outros aspectos, preveja: (1) o descomissionamento das atividades; (2) a reabilitação e atribuição de uso futuro das áreas degradadas; e (3) iniciativas que estimulem 
as capacidades da comunidade local para se desenvolver após o fim da atividade mineira (Sánchez, 2011; Ribeiro \& Mendes, 2013).

Expostos a uma situação hipotética em que os efeitos das atividades das seixeiras fossem sentidos mais fortemente no bairro/comunidade onde moram, a maioria dos interlocutores denunciaria os incômodos aos órgãos fiscalizadores $(60,2 \%)$ ou realizaria protestos junto à comunidade $(24,4 \%)$. Os demais demonstraram comportamentos de passividade, alegando que migrariam para outra área $(12,2 \%)$ ou conviveriam com os efeitos $(3,2 \%)$. A conduta mais "ativista" não está associada ao ponto de vista sobre um possível fechamento de todas as minas $\left(\chi^{2}=0,73\right.$; correção de Yates $\left.=0,37 ; p=0,53\right)$, nem com a preferência pela implantação de políticas de proteção ambiental no município $\left(\chi^{2}=1,37\right.$; correção de Yates $=0,88 ; \mathrm{p}=0,34$ ).

Ao avaliar as condições ambientais atuais, um percentual significativo da população consultada $(68,8 \%)$ concordaria em participar de alguma ação para a melhoria da qualidade de vida da população e do meio ambiente em Ourém. Este interesse está associado estatisticamente ao posicionamento declarado pelas pessoas para o cenário hipotético estabelecido anteriormente $\left(\chi^{2}=10,7\right.$; correção de Yates $=9,11 ; \mathrm{p}=0,002)$, independe da visualização de benefícios $\left(\chi^{2}=0,09\right.$; correção de Yates $=0,01$; $\mathrm{p}=0,89)$ e danos $\left(\chi^{2}=2,54\right.$; correção de Yates $=1,67$; $\mathrm{p}=0,19)$. A participação em palestras, ações de panfletagem/sensibilização e reuniões foram as formas hipotéticas de atuação apontadas mais frequentemente $(41,5 \%)$, seguida pela colaboração com a fiscalização $(27,2 \%)$. A cobrança de mais ações políticas e $\mathrm{o}$ incentivo às manifestações foram menos citadas, $19,9 \%$ e $11,3 \%$, respectivamente. Dentre as comunidades rurais visitadas, apenas duas fizeram protestos contra as atividades danosas das seixeiras: Sítio Nazaré e Mocambo.

$\mathrm{O}$ posicionamento neutro e indiferente foi apontado por 39,6\% daqueles que não colaborariam, enquanto os demais assumem um dos seguintes pontos de vista: não querer se envolver (22,9\%); já fazer a sua parte (18,7\%); não dispor de tempo (10,5\%); ou não ter preparação escolar para tal (8,3\%).

Notou-se, a partir do exposto, que os indivíduos apresentariam engajamento ambiental "ativista" caso os efeitos da mineração os atingissem com mais intensidade. Do contrário, grande parte dos consultados estaria apenas disposto a participar de ações/atividades que exigissem níveis menores de esforço e envolvimento, como: palestras, campanhas de sensibilização e no fornecimento de informações, ou nem isso.

Visualiza-se, portanto, um cenário em que a mineração de agregados e seus efeitos se tornaram habituais a ponto de acomodar a população, o que favorece a continuidade no ritmo de exploração e degradação do município. Registram-se, a seguir, alguns fatores que justificam estes comportamentos passivos: (1) o largo tempo transcorrido desde a chegada das mineradoras até hoje (mais de quatro décadas); (2) o medo das retaliações (alguns donos de seixeiras são conhecidos por essas práticas); (3) a descrença no poder público; e (4) a baixa importância atribuída às questões ambientais, quando comparada à urgência de outras necessidades como emprego e segurança. A esse respeito, Rodrigues (2006) afirmou que esta realidade é "produto do conjunto de processos e dinamismos sociais mais ou menos bloqueados e bloqueadores".

Nessa conjuntura, há necessidade de reestruturar as políticas e as intervenções socioambientais vigentes no estado, em atenção aos afetados pela 
mineração no município de Ourém. Nessa perspectiva, ressalta-se a Lei 1.784 , que dispõe sobre a Política Municipal do Meio Ambiente de Ourém (Ourém, 2013), que estabelece no art. 18, inciso $\mathrm{V}$, que os recursos do Fundo Municipal do Meio Ambiente (FMMA) devem ser destinados, dentre outros fins, à promoção de "atividades educativas e de mobilização da sociedade civil organizada num processo de defesa do meio ambiente e da salubridade ambiental", o que na prática não acontece.

\section{Conclusões}

A mineração de Ourém está associada a sérios agravos socioambientais nos locais onde está implantada. Registou-se que, mesmo com a exploração mineral acontecendo há décadas, em um ritmo acelerado, outros problemas, como segurança e emprego/trabalho, são mais visíveis e considerados prioritários para os entrevistados, em detrimento dos ambientais, principalmente aqueles produzidos pela extração de agregados. As pessoas que mais se sensibilizam e exteriorizam suas preocupações com o meio ambiente são as que possuem idade avançada, ocupação profissional fixa e moram há bastante tempo no município.

Os interlocutores mencionaram mais danos do que benefícios advindos da mineração no município, o que é evidenciado pelas irrisórias medidas reparadoras de danos, baixa empregabilidade nos empreendimentos e falta de ações para melhoria da qualidade de vida da população. Os prejuízos da atividade ao meio físico são os mais percebidos, devido às mudanças na paisagem e nos modos de vida; entretanto a população não sente de forma efetiva os efeitos adversos do setor à saúde.
A articulação popular para exigir reparação/ mitigação de danos e contrapartidas sociais é rara e pontual. As pessoas demonstraram uma tendência para atitudes ativistas e/ou questionadoras apenas quando forem afetadas mais diretamente. Enquanto isso, a maioria mantém-se acomodada e/ou, de certa forma, coagida/pressionada a não denunciar ou reclamar dos efeitos da atividade, o que contribui para a continuação e ampliação da exploração mineral predatória no município.

Por fim, acredita-se, que este estudo pode nortear a implementação de medidas de monitoramento e fiscalização dos empreendimentos mineiros, além de estimular a formulação de políticas públicas, a mobilização social e o planejamento de ações mais sustentáveis para a manutenção dos modos de vida e aproveitamento socioeconômico e cultural do meio ambiente.

\section{Referências}

ABNT - Associação Brasileira de Normas Técnicas. NBR 14063: Óleos e graxas - Processos de tratamento em efluentes de mineração. Rio de Janeiro, 1998.

Adeola, A.; Olushola, B. N. Environmental Challenges of Quarry Activities in Part of Ikere-Ekiti, Ekiti state, Nigeria. International Journal of Science and Research (IJSR), 5(11), 576-581, 2016.

Aguirre, A. de B.; Hennies, W. T. Logística para agregados (brita e areia) em grandes centros urbanos. REM: Revista Escola de Minas, 63(4), 639-644, 2010.

Albuquerque, U. P. de; Lucena, R. F. P. de; Cunha, L. V. F. C. da. Métodos e Técnicas na Pesquisa Etnobiológica e Etnoecológica. Recife, PE: NUPPEA, 2010.

Amorim, N. A.; Conceição, T. L. de A.; Ferreira, P. A. Mineração de Agregados e Saúde Pública: uma perspectiva socioambiental nas comunidades rurais Sagui 1 e 2. Educação, 
Tecnologia e Cultura - E.T.C., (14), 1-13, 2016.

Andrade, L.; Braga-Filho, H. A interiorização da violência social: uma análise do interior paulista. DRd-Desenvolvimento Regional em debate, 6(1), 192-217, 2016.

Anuário do Pará. Anuário do Pará 2017-2018. Belém: Jornal Diário do Pará, 8(8), 2017. 876 p.

Arango, S.; Jaramillo, P.; Olaya, Y.; Smith, R.; Restrepo, O. J.; Saldarriaga-Isaza, A.; Arias-Gaviria, J.; Parra, J.F.; Larsen, E.R. Simulating mining policies in developing countries: The case of Colombia. Socio-Economic Planning Sciences, 60, 99-113, 2017. doi: 10.1016/j.seps.2017.04.002

Araujo, E. R.; Olivieri, R. D.; Fernandes, F. R. C. Atividade mineradora gera riqueza e impactos negativos nas comunidades e no meio ambiente. In: Fernandes, F. R. C.; Alamino, R. de C. J.; Araujo, E. R. (Eds.). Recursos Minerais e Sociedade: impactos humanos, socioambientais, econômicos. Rio de Janeiro: CETEM, 2014. p. 1-12.

Ayelazuno, J. A. The 'new extractivism' in Ghana: a critical review of its development prospects. The Extractive Industries and Society, 3(2), 292-302, 2014. doi: 10.1016/j. exis.2016.01.006

Bacci, D. D de L. C.; Landim, P. M. B.; Eston, S. M. de. Aspectos e impactos ambientais de pedreira em área urbana. REM: Revista Escola de Minas, 59(1), 47-54, 2006.

Bardin, L. Análise de conteúdo. 4. ed. Lisboa: Edições 70, 2010.

Blengini, G. A., Garbarino, E., Šolar, S., Shields, D. J., Hámor, T., Vinai, R., Agioutantis, Z. Life Cycle Assessment guidelines for the sustainable production and recycling of aggregates: the Sustainable Aggregates Resource Management project (SARMa). Journal of Cleaner Production, 27, 177-181, 2012.

Bossi, D.; Chammas, D.; Milanez, B.; Carneiro, M. S. Reféns da riqueza de nossa terra: os impactos da mineração sobre as comunidades. In: Conflitos no campo, 2010. p. 65-74. Disponível em: <http://www.ufjf.br/poemas/files/2014/07/ Bossi-2010-Ref\%C3\%A9ns-da-riqueza-de-nossa-terra. pdf>. Acesso em: nov. 2019.

Brasil. Lei $n^{\circ}$ 9.503, de 23 de setembro de 1997. Institui o Código de Trânsito Brasileiro. Brasília: DOU de 24/9/1997.
Brito, B; Barreto, P. A eficácia da aplicação da lei de crimes ambientais pelo Ibama para proteção de florestas no Pará. Revista de Direito Ambiental, (46), 35-45, 2006.

Brito, T. P.; Klen, A. C.; Silva, J. F. da; Alves, M. da S. Avaliação socioeconômica e a percepção ambiental dos moradores de Mãe do Rio - Pará - Brasil. Conexão Ciência e Tecnologia, 9(3), 23-33, 2015.

Carvalho, M. B. M.; Silva, R. T. L.; Coutinho, P. W. R.; Neto, C. F. O.; Lima, L. G. S. Cadeia Produtiva de Agregados de Construção em Mineradora no Município de Ourém - Pará. Enciclopédia Biosfera, 9(16), 2524-2539, 2013.

Carvalho, T. S.; Domingues, E. P. Projeção de um cenário econômico e de desmatamento para a Amazônia Legal brasileira entre 2006 e 2030. Nova Economia, 26(2), 585$621,2016$.

CETEM - Centro de Tecnologia Mineral. Manual de Agregados para Construção Civil. Rio de Janeiro: 2009.

Congilio, C. R.; Moreira, E. do S. S. A resistência aos grandes projetos de mineração do ferro no sudeste paraense. Revista Políticas Públicas, Número Especial, 105-115, 2016.

Correia J. H. G.; Pereira P. Extracção de areia na praia de Calhetona (Ilha de Santiago, Cabo Verde): causas, processos e consequências. Journal of Integrated Coastal Zone Management / Revista de Gestão Costeira Integrada, 16(2), 195-206, 2016.

Creswell, J. W. Research design: Qualitative, quantitative and mixed methods approaches. 3. ed. SAGE, 2009. 251 p.

Diegues, A. C. (Org.). Os saberes tradicionais e a biodiversidade no Brasil. São Paulo: MMA/COBIO/NUPAUB/ USP, 2000. $211 \mathrm{p}$.

DNPM - Departamento Nacional de Produção Mineral. Informe mineral do Estado do Pará: janeiro - junho de 2017. DNPM, 2017.

Faleiro, F. F.; Lopes, L. M. Aspectos da Mineração e Impactos da Exploração de Quartzito em Pirenópolis-GO. Ateliê Geográfico, 4(11), 148-162, 2010.

FANEP - Fundação Socioambiental do Nordeste Paraense. Diagnóstico e Planejamento de Desenvolvimento do Território Rural do Nordeste Paraense. Capanema, 2006. 
Disponível em: <http://sit.mda.gov.br/download/ptdrs/ ptdrs_territorio061.pdf>. Acesso em: nov. 2018.

FAPESPA - Fundação Amazônia de Amparo a Estudos e Pesquisa. Estatísticas Municipais Paraenses: Ourém. Belém: Diretoria de Estatística e de Tecnologia e Gestão da Informação, 2012. 61 p.

Farias, C. E. G. Mineração e meio ambiente no Brasil. Relatório preparado para o CGEE/PNUD, 2002. Disponível em: <http://www.scribd.com/doc/52441018/2/caracteristicas-gerais-da-mineracao-no-brasil-e-o-meio $>$. Acesso em: abr. 2018.

Fearnside, P. M. Hidrelétricas na Amazônia: impactos ambientais e sociais na tomada de decisões sobre grandes obras. Manaus: Editora do INPA, 2015.

Ferreira, L. F.; Coutinho, M. C. B. Educação Ambiental em estudos do meio: a experiência do Bioma Educação Ambiental. In: Serrano, C. (Org.). A Educação das Pedras: ecoturismo e educação ambiental. São Paulo: Chronos, 2000. p. 171-188.

Ferreira, M. J.; Cordeiro, J.; Calazans, G. M.; Santiago, G. L. A.; Cordeiro, J. L.; Guimarães, J. C. S. Percepção da população de São Gonçalo do Rio Abaixo (MG) acerca dos impactos socioambientais e econômicos desencadeados pela explotação de minério de ferro na mina de Brucutu. Research, Society and Development, 7(5), 1-26, 2018.

Furtado, A. M. M.; Ponte, F. C. da. Mapeamento de unidades de relevo do Estado do Pará. Revista GeoAmazônia, 2(2), 56-67, 2013.

Geovane, J.; Furtado, L. L.; Souza, A. S. Análise dos Impactos Ambientais Provenientes da Mineração de Seixo em Ourém (PA). In: Anais do Congresso de Mineração da Amazônia. Belém, 7 de nov. 2012. Disponível em: <http:// www.ebah.com.br/content/ABAAAfh7sAK/congresso-artigoseixo> Acesso em: 21 nov. 2017.

Gil, A. C. Métodos e técnicas de pesquisa social. São Paulo: Editora Atlas, 6. ed, 2008.

Gotelli, N. J.; Ellison, A. M. Princípios de estatística em ecologia. Porto Alegre: Artmed, 1. ed., 2010. 528 p.

Guimarães, C. L.; Milanez, B. Mineração, impactos locais e os desafios da diversificação: revisitando Itabira. Desen- volvimento e Meio Ambiente, 41(2), 215-236, 2017.

Gunzburger, Y.; Agnoletti, M-F.; Deshaies, M.; Ferey, S.; Raggi, P. Social perception of unconventional gas extraction on the outskirts of a former coal-mining area in Northeast France. The Extractive Industries and Society, 4 (1), 5362, 2017.

Hamilton, L. C.; Hartter, J.; Safford, T. G.; Stevens, F. R. Rural Environmental Concern: Effects of Position, Partisanship, and Place. Rural Sociology, 79(2), 257-281, 2014. doi: $10.1111 /$ ruso. 12023

Hinwood, A. L.; Heyworth, J.; Tanner, H.; Mccullough, C. D. Mine Voids Management Strategy (II): Review of potential health risks associated with Collie pit lakes. Perth, Australia: Edith Cowan University, 2009. 125 p.

IBGE - Instituto Brasileiro de Geografia e Estatística. Censo Demográfico 2010 - Ourém, 2010. Disponível em: <http:// cod.ibge.gov.br/2VT7G $>$ Acesso em: nov. 2017.

Ibrahim, W. H. W.; Marinie, E.; Yunus, J.; Asra, N.; Mohd Sukor, K. Air quality assessment on human well-being in the vicinity of quarry site. IOP Conference Series: Earth and Environmental Science, 117, 2018. doi: 10.1088/17551315/117/1/012010

IBRAM - Instituto Brasileiro de Mineração. Informações e Análises da Economia Mineral Brasileira. Brasília: IBRAM, 7 ed., 2012. 68 p.

Jerônimo, R. N. T.; Souza, R. V. C. Psicologia ambiental: um estudo acerca da resistência frente à mineração em Içara, SC. Psicologia \& Sociedade, 27(1), 80-86, 2015.

Johnson, R. B.; Onwuegbuzie, A. J. Mixed Methods Research: a research paradigm whose time has come. Educational Researcher, 33(7), 14-26, 2004.

Jones, R. E.; Dunlap, R. E. The social bases of environmental concern: Have they changed over time. Rural Sociology, 57(1), 28-47, 1992.

Kitula, A. G. N. The environmental and socio-economic impacts of mining on local livelihoods in Tanzania: A case study of Geita District. Journal of Cleaner Production, 14, 405-414, 2006.

La Serna, H. A.; Rezende, M. M. Agregados para Constru- 
ção Civil. In: Brasil, Departamento Nacional de Produção Mineral. (Org.). Economia Mineral do Brasil. Brasília: DNPM, 2013. p. 602-635.

Li, Q.; Stoeckl, N.; King, D.; Gyuris, E. Exploring the impacts of coal mining on host communities in Shanxi, Chinausing subjective data. Resources Policy, 53, 125-134, 2017.

Lobato, G. de J. M.; Lucas, F. C. A.; Tavares-Martins, A. C. C.; Jardim, M. A. G.; Martorano, L. G. Diversidade de uso e aspectos socioambientais de quintais urbanos em Abaetetuba, Pará, Brasil. Revista Brasileira de Agroecologia, 12(2), 95-105, 2017.

Lopes-Passos, F.; Coelho, P.; Dias, A. (Des)territórios da mineração: planejamento territorial a partir do rompimento em Mariana, MG. Cadernos Metrópole, 19(38), 269-297, 2017.

Mancin, R. C. Estagnação das pesquisas na área gera expectativas negativas. 2012. Disponível em: <http:// www1.folha.uol.com.br/fsp/mercado/53864-estagnacao-das-pesquisas-na-area-gera-expectativas-negativas.shtml> Acesso em: 24 nov. 2017.

Marconi, M. de A.; Lakatos, E. M. Fundamentos de metodologia científica. São Paulo: Atlas, 7. ed., 2010.

Matlaba, V. J.; Mota, J. A.; Maneschy, M. C.; Santos, J. F. dos. Social perception at the onset of a mining development in Eastern Amazonia, Brazil. Resources Policy, 54, 157-166, 2017. doi: 10.1016/j.resourpol.2017.09.012

Matos, A. Oureana de além-mar, Ourém, terra de Moura: organização e introdução de elementos novos da história de Ourém-PA. Ourém: Edição Virtual, 2007. 126 p. Disponível em: $<$ https://www.fundacaocetap.com.br/uploads/237/concursos/133/anexos/c17e4b289f2075346492fddaf9e94d51. pdf.> Acesso em: mar. 2018.

Matos, R.; Ferreira, R. N. Brasil em crise e o emprego formal no Sudeste. Caminhos de Geografia, 18(61), 150-164, 2017.

Mechi, A.; Sanches, D. L. Impactos ambientais da mineração no Estado de São Paulo. Estudos avançados, 24(68), 209-220, 2010. doi: 10.1590/S0103-40142010000100016

Mello, A. H. de; Gama, M. F. F.; Oliveira, G. F. de; Silva, J. C. da. Diagnóstico da degradação ambiental em áreas de extração de argila em Marabá-PA. Agroecossistemas, 9(1), 45-61, 2017.
Olusegun, O.; Adeniyi, A.; Adeola, G.T. Impact of Granite Quarrying on the Health of Workers and Nearby Residents in Abeokuta Ogun State, Nigeria. Ethiopian Journal of Environmental Studies and Management (EJESM), 2, 21-26, 2009. doi: 10.4314/ejesm.v2i1.43497

Ourém, Prefeitura Municipal. Plano Municipal de Educação - PME - 2015-2025. Ourém, PA: 2015.

Ourém. Lei Municipal 1.784, de 28 de novembro de 2013. Dispõe sobre a Política Municipal de Meio Ambiente de Ourém, Estado do Pará e das outras providencias. Ourém: DOU: $25 / 11 / 2013$.

Palheta da Silva, J. M.; da Silva, C. N. Juruti: uma comunidade amazônica atingida pela mineração. Geographia, 18(36), 128-148, 2016.

Penafiel, A. P. P. Da mina de Socavão à mina a céu aberto: os novos pactos no caso do centro de mineração de Hualgayoc, Cajamarca, Peru. Caderno Eletrônico de Ciências Sociais, 5(1), 115-135, 2017. doi: 10.24305/cadecs.v5i1.2017.17774

Pinheiro, C. do S. da S. Extração de areia e seixo - Desenvolvimento ou degradação? O caso de Porto Grande/AP. Macapá, Dissertação (Mestrado em Gestão de Recursos Naturais e Desenvolvimento Local na Amazônia) - UFPA, 2016.

Pires, G. S. Gerenciamento produtivo e logístico no setor mineral não metálico do Estado do Pará: um estudo multicaso da competitividade organizacional. Belém, Dissertação (Mestrado em Administração) - UNAMA, 2014.

Plank, S. V. D.; Walsh, B., Behrens, P. The expected impacts of mining: Stakeholder perceptions of a proposed mineral sands mine in rural Australia. Resources Policy, 48, 129136, 2016.

Rabelo, A. M. P. Qualidade Ambiental e Mineração: percepção de moradores de Carmo da Mata/MG. Pesquisa em Educação Ambiental, 12(1), 129-145, 2017.

Rampazzo, S. E. A questão ambiental no contexto do desenvolvimento econômico. REDES, 1(2), 197-222, 1996.

Ribeiro, J. C. J.; Mendes, S. F. A participação no fechamento de mina no direito comparado. Veredas do Direito, 10(20), 23-54, 2013. 
Rodrigues, E. V. de A. Escassos Caminhos - Os processos de imobilização social dos beneficiários do R.M.G. em Vila Nova de Gaia. Porto (Portugal), Tese (Doutorado em Letras), Universidade do Porto, 2006.

Rodrigues, M. L.; Malheiros, T. F.; Fernandes, V; Darós, T. D. A Percepção Ambiental como Instrumento de Apoio na Gestão e na Formulação de Políticas Públicas Ambientais. Saúde e Sociedade, 21(3), 96-110, 2012.

Rodrigues, V. P.; Paiva, C. A. de; Marquis, D. E. P.; Pereira, L. G.; Prado-Filho, J. F. do. Percepção dos moradores do distrito de Antônio Pereira, Ouro Preto - MG, sobre meio ambiente, saneamento básico e riquezas ambientais locais. Revista ELO - Diálogos em Extensão, 6(2), 25-35, 2017.

Sanchez, L. E. Planejamento para o fechamento prematuro de minas. REM: Revista Escola de Minas, 64(1), 117-124, 2011.

Santos, B. A. dos. Recursos minerais da Amazônia. Estudos Avançados, 16(45), 123-152, 2002.

Santos, E. G. dos; Oliveira-Neto, R.; Abichequer, L. A.; Souza, L. E. de; Marques, R.; Gonçalves, Í. G. Recuperação ambiental na disposição de estéril em mineração de calcário. Revista Monografias Ambientais, 14, 14-32, 2015. doi: 105902/2236130818713

Santos, F. P. dos; Souza, L. B. e. Estudo da percepção da qualidade ambiental por meio do método fenomenológico. Mercator, 14(2), 57-74, 2015.

Shen, J.; Saijo, T. Reexamining the relations between socio-demographic characteristics and individual environmental concern: Evidence from Shanghai data. Journal of Environmental Psychology, 28(1), 42-50, 2008.

Shi, X.; He, F. The Environmental Pollution Perception of Residents in Coal Mining Areas: A Case Study in the Hancheng Mine Area, Shaanxi Province, China. Environmental Management, 50(4), 505-513, 2012.

Silva, F. P. da; Moura, G. J. B. de; Santos, C. A. B. dos. Representações dos moradores do entorno das áreas de exploração sobre a importância e impactos da mineração. Geosul, 33(66), 128-146, 2018.

Silva, M. G. S.; Souza, M. R. G. Itabira - Vulnerabilidade Ambiental: impactos e riscos socioambientais advindos da mineração em área urbana. In: Anais do XIII Encontro da Associação Brasileira de Estudos Populacionais. Ouro Preto, 4 de nov., 2012.

Silva, R. F. T. da; Ramos, V. D. e A. Os contrastes da mineração e a busca do desenvolvimento sustentável a partir da implementação de medidas mitigadoras, compensatórias e de práticas voluntárias. Revista de Direito, Economia e Desenvolvimento Sustentável, 1(2), 139-155, 2015.

Small, M. L. How to conduct a mixed methods study: Recent trends in rapidly growing literature. Annual Review Sociology, 37, 57-86, 2011.

SOS Mata Atlântica. Guia de Aplicação da Consulta Pública Ambiental: caracterização ambiental por percepção. São Paulo, 2015.

Sousa, E. R. de; Castro, A. C. L. de; Azevedo, J. W. J.; Araujo, G. M. C. de. Caracterização socioeconômica e percepção ambiental das populações locais em áreas propostas para implantação de unidades de conservação no município de Bacabeira-MA. Espacios, 37(26), 15-20, 2016.

Souza, J. T. M.; Pena, H. W. A.; Silva, B. E. B. Análise espacial das atividades de mineração: expansão das áreas de Cavas de seixo e areia no município de Ourém, PA. Revista Observatorio de la Economía Latinoamericana, (215), 2016. Disponível em: < http://www.eumed.net/cursecon/ ecolat/br/16/ourem.html>. Acesso em: 27 mar. 2018.

Tuan, Y. Topofilia: um estudo da percepção, atitudes e valores do meio ambiente. São Paulo: Difel, 1980.

UN - United Nations. Designing Household Survey Samples: Practical Guidelines. UN: New York, 2008.

Van Liere, K. D.; Dunlap, R. E. The social bases of environmental concern: A review of hypotheses, explanations and empirical evidence. The Public Opinion Quarterly, 44, 181-197, 1980.

Vieira, C. I. de P.; Viana, B. A. da S. Áreas de Extração Mineral para Construção Civil em Teresina-PI: aspectos físicos e seus impactos socioambientais. Revista Equador, 5(3), 99-119, 2016.

Vorkinn, M.; Riese, H. Environmental concern in a local context: the significance of place attachment. Environment and Behavior, 33(2), 249-263, 2001. 
Waiselfisz, J. J. Mapa da violência 2012: os novos padrões da violência homicida no Brasil. 1 ed. São Paulo: Instituto Sangari, 2011. 245 p.

Waiselfisz, J. J. Mapa da violência 2016: homicídios por armas de fogo no Brasil. 1 ed. Brasília: Flacso Brasil, 2015. $71 \mathrm{p}$.

White, M. J.; Hunter, L. M. Public perception of environmental issues in a developing setting: environmental concern in coastal Ghana. Social Science Quarterly, 90(4), 960-982, 2009.

Whyte, A. V. T. La perception des I'environment: lignes directrices méthodologiques pour les études sur le terrain. Paris: UNESCO, 1977. 